\title{
A ESTÉTICA RELACIONAL E O ESPECTADOR COMO PARTICIPANTE DO FENÔMENO TEATRAL
}

\author{
Stenio José Paulino Soares \\ Ator e professor do curso de Licenciatura em Teatro da Universidade Estadual do Paraná (UNESPAR) \\ Doutorando do Programa de Pós-Graduação em Artes Cênicas da Universidade de São Paulo (USP) \\ E-mail: steniosoares@gmail.com
}

A esfera das relações humanas como lugar da obra de arte sempre foi um dos assuntos mais caros à arte teatral. Este aspecto da estética relacional nos provoca uma reflexão sobre as artes cênicas, embora Nicholas Bourriaud oriente sua reflexão através das mudanças evidentes nas artes visuais. Ainda que percebamos que as artes cênicas também foram afetadas por proposições da estética relacional e sofreram mudanças significativas quanto à obra de arte cênica, devemos admitir que a relação de intersubjetividade entre os artistas teatrais, a cena e os espectadores precede a própria noção da arte moderna, e se remete às formas elementares da vida em sociedade quando os sacerdotes, o acontecimento do ritual e os participantes se relacionavam de maneira a elevar-se a um estado sublime. $O$ presente trabalho resulta da nossa experiência com o work in progress "Negras memórias" e a observação de encenações contemporâneas. Conforme refletiremos sobre a estética relacional, também buscaremos evidenciar o que foi alterado, especialmente, no estatuto da obra de arte cênica. Discutiremos o fenômeno da interatividade, na perspectiva do fenômeno teatral que revisita através das encenações o princípio das relações humanas como lugar da arte.

\section{Palavras-chave}

Estética Relacional. Espectador. Fenômeno Teatral.
The sphere of human relations as a place of work of art has always been one of the most expensive issues to theatrical art. This aspect of relational aesthetics motivates us to reflect on the performing arts, although Nicholas Bourriaud orient its reflection through the changes in the visual arts. We understand that the performing arts have also been affected by proposals of relational aesthetics and they have undergone significant changes of the performing art work. We must admit that intersubjectivity relationship between theater artists, the scene and the spectators above the very notion of modern art: they recall the elementary forms of social life when the priests, the ritual and the participants were related as to amount to a sublime state. This work is the result of our experience with the work in progress "Black memories" and the observation of contemporary theatre. As we reflect on the relational aesthetics, also seek to highlight what has changed, especially in the status of the performing art work. We will discuss the interaction phenomenon from the perspective of the theatrical phenomenon that revisits through the principle of human relations as a place of art. Keywords

Relational Aesthetics. Spectator. Theatrical Phenomenon. 
$O$ que elas (a intersubjetividade, a interação) produzem são espaços tempos-relacionais, experiências inter -humanas que tentam se libertar das restrições ideológicas da comunicação de massa; de certa maneira, são lugares onde se elaboram sociabilidades interativas, modelos críticos, momentos de convívio construído (Bourriaud, 2009, p.62).

\section{Introdução}

A estética relacional, argumentada pelo filósofo Nicholas Bourriaud, compreende uma diversidade de expressões artísticas, que revelam um fenômeno no âmbito da linguagem. Inicialmente, esse fenômeno exige um esforço para ser compreendido, por que se acerca de significações sem se encerrar nelas. Assim, no fenômeno cênico, algumas construções de linguagem se expressam por sinais percebidos em virtude da corporeidade, resultando em um sentido incorpóreo.

"A esfera das relações humanas como lugar da obra de arte" (Bourriaud, 2009, p.61) sempre foi o assunto mais caro à arte teatral e, certamente por este motivo, o filósofo nos provoca uma reflexão sobre as artes cênicas, embora seu ensaio sobre a estética relacional se oriente pelas mudanças evidentes nas artes visuais, integrando novas linguagens que não eram abarcadas pela História da Arte Moderna. No entanto, ainda que percebamos que nas artes cênicas também se manifestaram aspectos que se aproximam à estética relacional, provocando, sobretudo, mudanças significativas quanto ao estatuto da obra de arte teatral, devemos admitir que a relação de intersubjetividade entre os artistas teatrais, a cena e os espectadores precede à própria noção de arte moderna. Victor Hugo, um dos principais intelectuais do romantismo, já reconhecia que aspectos estéticos relacionais presentes na cena se assemelhavam às formas elementares da vida religiosa, quando sacerdotes e participantes se relacionavam em rituais de maneira a se elevarem a um estado sublime.

[...] A antiguidade nada tem de mais solene, nada de mais majestoso. Seu culto e sua história se misturam ao seu teatro. Seus primeiros atores são sacerdotes; seus jogos cênicos são cerimônias religiosas, festas nacionais" (Hugo, 2012, p. 21).

Embora com papéis definidos, todas as pessoas envolvidas em um ritual religioso participam com atos e práticas comuns. Essa condição de participantes interativos, presente no fenômeno religioso, é percebida tanto nos jogos e brincadeiras populares de grupos étnicos na contemporaneidade quanto na gênese do teatro ocidental, como lemos em Aristóteles e em Platão. No entanto, são nos escritos de Antonin Artaud (2010), no início do século XX, que encontramos claramente a proposição de um teatro ritual, considerando o fenômeno cênico como um desdobramento cultural do fazer ritualístico religioso.

No contexto da arte relacional, a intersubjetividade e a interação, tal como destaca Bourriaud (2009), não são procedimentos teóricos ou aspectos coadjuvantes da prática artística. A arte relacional considera estes aspectos como "ponto de partida e de chegada, em suma, como principais elementos a dar forma à sua atividade" (Bourriaud, 2009, p.62).

Ao longo deste artigo, com base em reflexões sobre a estética relacional, buscarei evidenciar o que foi alterado nas artes cênicas, especialmente na obra teatral. Com isso, 
traçarei um breve caminho que, longe de ambicionar conclusões, buscará tão-somente esboçar um quadro teórico a fim de compreender a abordagem do fenômeno da interatividade feita por alguns artistas teatrais, a partir de suas encenações, as quais contemporaneamente, revisitam o princípio das relações humanas como lugar da arte.

\section{A intersubjetividade} na teoria do drama moderno

Sabemos que o teatro ocidental, desde as convenções postuladas no contexto do renascimento, propunha à forma dramática uma autonomia da encenação diante do espectador, colocando-o na condição de observador contemplativo. No entanto, não é incorreto afirmar que as relações de intersubjetividade sempre estiveram presentes nas artes cênicas. $O$ fenômeno da cena não se limita a um conjunto de artifícios técnicos somados à atuação de atores, orquestrados por um encenador que coloca sobre um palco a expressão cênica de um texto. Antes do texto existe o argumento, sendo que o próprio texto pode ser construído de diversas maneiras. Mesmo assim, a obra teatral sempre exigiu uma relação entre artistas, encenação e espectadores, ainda que submetesse o espectador ao distanciamento, como aconteceu no teatro naturalista e sua vertente burguesa (Szondi, 2004).

Afirmamos que as relações de intersubjetividade entre os artistas teatrais, a cena e os espectadores se remetem às formas elementares da vida religiosa e acontecem de maneira a fazer os participantes se elevarem a um estado sublime. Quando nos remetemos à gênese antropológica das artes cênicas, tam- bém consideramos que sua tradição ocidental se transformou de tal maneira que no caso do teatro moderno (Szondi, 2011), especialmente na expressão do naturalismo, a relação interativa entre artistas, cena e espectadores foi relegada, e o texto enaltecido enquanto dramaturgia. $\mathrm{O}$ teatro moderno assume a forma dramática, enraizado no raciocínio dialético de Aristóteles, quando as ações se desenvolvem de maneira que a contradição entre os fatos resulte em uma solução-síntese.

Sendo o drama sempre primário, sua época é sempre o presente. O que não indica absolutamente que é estático, senão somente que há um tipo particular de decurso temporal no drama: o presente passa e se torna passado, mas enquanto tal já não está mais presente em cena. Ele passa produzindo uma mudança, nascendo um novo presente de antítese (Szondi, 2011, p. 32).

Sob a forma dramática, os espectadores estão na condição de receptores, plateia para "contemplar" a encenação. Segundo Peter Szondi (2011), o drama moderno tem a tendência de reproduzir na cena a estrutura do diálogo, como forma representativa da relação intersubjetiva dos personagens no texto. No entanto, no final do séc. XIX e início do séc. XX, Stanislavski e Meyerhold já salientavam que as obras de Anton Tchékhov desafiavam os limites de um realismo naturalista, porque não se tratavam de dramas convencionais: elas não reproduziam a estrutura do diálogo, tal como os dramas realistas vigentes, e a intersubjetividade dos personagens era criada em torno de uma conversação com longas pausas e textos que refletiam a própria condição do personagem. Vejamos o que Szondi afirma sobre os textos de Tchékhov:

[...] monólogos debruçados de 
réplicas, como manchas coloridas em que se condensa o sentido do todo. $\mathrm{E}$ das auto-análises resignadas, que quase todas as personagens expressam uma a uma, vive a obra, escrita em função delas (Szondi, 2011, p. 50).

A especificidade da linguagem tchékhoviana explodia a centralidade do texto e demandava uma forma diferente para sua encenação. O drama moderno se revelava em crise e, ao passo que o texto se tornava insuficiente para a obra, ele também exigia dos encenadores a criação de uma linguagem cênica que fosse além da representação do texto. $E$, nesse contexto, Vsévolod Meyerhold, aponta a responsabilidade de se assumir o espectador como um novo criador da cena:

Enfim, depois do autor, do diretor e do ator, o método de estilização supõe no teatro um quarto criador: o espectador. A nova concepção de direção obriga o espectador a completar pela sua imaginação as alusões feitas em cena" (Meyerhold, 1969, p. 38) (grifo do autor).

Diante das novas obras de autores como Tchékhov, Ibsen e Strindberg, segundo Meyerhold (1969), a linguagem da encenação teatral precisava provocar no espectador uma experiência de pensamento. Ou seja, o espectador experimenta a obra cênica e a partir dela também cria. Ao assumir o espectador como um quarto criador da obra cênica, Meyerhold adianta uma nova mudança no estatuto da obra de arte cênica: a cena apresenta necessariamente uma relação de intersubjetividade com o espectador, ainda que não se fale em interatividade.
A intersubjetividade

e a interação na cena como acontecimento

\begin{abstract}
A estética relacional constitui não uma teoria da arte, que suporia o enunciado de uma origem e de um destino, e sim uma teoria da forma (Bourriaud, 2009, p. 26).
\end{abstract}

Discutimos, anteriormente, que a intersubjetividade é um fenômeno inerente à obra cênica. Vimos que as convenções postuladas sobre o drama desde o renascimento até o romantismo limitou o espectador à condição de observador contemplativo da cena. Em virtude da natureza dramatúrgica de autores como Tchékhov, a encenação como representação do texto passa a ser questionada. Nesse contexto, Meyerhold propõe o deslocamento do espectador da condição de contemplador para criador da obra cênica, a partir da sua experiência de pensamento. Assim, observamos que a subjetividade do espectador passa a ser um elemento criativo, evidenciando o aspecto de intersubjetividade da cena.

A experiência de intersubjetividade e interação na obra teatral tem um contexto específico, atribuído pelo caráter de acontecimento da cena. Por outro lado, há também um extensivo debate em torno da performance, o que desloca o teatro do centro das discussões, inserindo a dança e o estudo da performance.

Considerando a história da performance, há quem prefira situá-la em um campo comum tanto das artes cênicas como das artes visuais.

Ao que concerne às artes cênicas, a noção de acontecimento compreende um espaçotempo específico de relação com a obra. As relações de intersubjetividade durante 0 ato cênico constroem um mundo particular, 
visto que essa prática artística propicia uma convivência com o outro. Nesse sentido, quando uma obra teatral propõe a interatividade, ela, de alguma maneira, aproxima-se à forma estética relacional:

[...] a forma de uma obra de arte nasce de uma negociação com o inteligível que nos cabe. Através dela, o artista inicia um diálogo. A essência da prática artística residiria, assim, na invenção de relações entre sujeitos; cada obra de arte particular seria a proposta de habitar um mundo em comum, enquanto o trabalho de cada artista comporia um feixe de relações com o mundo, que geraria outras relações, e assim por diante, até o infinito" (Bourriaud, 2009, p. 31).

Segundo Hans-Thies Lehmann (2007), a forma dramática foi o cânone, o princípio formal, que interferiu estruturalmente nas regras das artes cênicas. Embora o autor argumente que o teatro "pós-dramático" seja tanto uma crítica à forma dramática quanto também o deslocamento da obra de arte cênica para o acontecimento, o que houve foi a reafirmação do caráter antropológico do acontecimento, essência ou princípio racional do fenômeno da cena.

[...] Foi determinante para a estética teatral o deslocamento da obra para o acontecimento. É certo que o ato da observação, as reações e as "respostas" latentes, ou mais incisivas dos espectadores desde sempre haviam constituído um fator essencial da realidade teatral, mas nesse momento se tornam um componente ativo do acontecimento, de modo que a ideia de uma construção coerente de uma obra teatral acaba por se tornar obsoleta: um teatro que inclui as ações e expressões dos espectadores como um elemento de sua própria constituição não pode se fechar em um todo nem do ponto de vista prático nem teórico. Assim, o acontecimento teatral torna explícitas tanto a processualidade que lhe é própria quanto a imprevisibilidade nela implícita". (Lehmann, 2007, p. 100).

Quando observamos uma obra teatral que propõe a intersubjetividade e interação com o outro/espectador, não podemos negligenciar o aspecto de acontecimento deste fenômeno. Esta relação dinâmica faz compreender uma atividade teatral dialogando com a forma relacional.

Deve-se ressalvar que, embora apreciemos o estudo de Hans-Thies Lehmann, que revela significativas observações acerca da teoria crítica de teatro, percebemos problemas no seu conceito de "teatro pós-dramático". Mesmo que o autor não tenha a intenção de reforçar uma historiografia cronológica do teatro (Lehmann, 2010), há de se considerar um deslize do crítico ao empregar o conceito "pós-dramático". O uso do prefixo "pós" (do latin post, atrás de; depois de; após, em seguida) implica considerar que a forma "pós-dramática" é uma "fase" posterior ou aquilo que vem depois da forma dramática. Se Lehmann desenvolve o conceito de "pós-dramático" considerando o mesmo como uma reação crítica à forma dramática, nesse sentido, enquanto significante linguístico, "pós-dramático" é um termo ambíguo. Os aspectos que o autor identifica como "signos do teatro pós-dramático"1 estão presentes na forma dramática, o que nos leva a entender que uma tendência de resistir à forma dramática é inerente a ela mesma."

\footnotetext{
${ }^{1}$ A saber: a parataxe como des-hierarquização dos recursos teatrais (ator, luz, som, cenografia, etc); a simultaneidade dos recursos teatrais; a superabundância dos elementos cênicos; a musicalização (música valorizada como elemento cênico); cenografia como dramaturgia visual; e a corporeidade, ou seja, o corpo não como portador de sentido, mas como substância física e gesticulação. (Lehmann, 2007).
} 
O drama, enquanto forma, não foi superado pelo teatro na contemporaneidade, visto que percebemos expressões da permanência de questionamentos, sobretudo, referente ao aspecto relacional da obra teatral. $O$ que Lehmann identifica como "teatro pós-dramático" são teatralidades que eclodem críticas à forma dramática, sem sua completa negação. Estas expressões se manifestam como alternativas discursivas, cuja ascensão está atrelada às narrativas de legitimação com determinado vínculo social da obra teatral. Nesse sentido, situo o trabalho dos encenadores José Celso Martinez Correa, Pina Bausch e Angélica Lidell como expressões que situam essa "crise das narrativas" (Lyotard, 1989) no contexto das artes cênicas.

Em Pina Bausch, especialmente no espetáculo 1980, as relações da sua dança-teatro com a crítica à forma dramática como estrutura narrativa ficam evidentes. A construção das cenas se destaca como o resultado de um inventário, um levantamento detalhado de gestos corporais que constroem a corporeidade de cada ator/bailarino. Os corpos dos bailarinos nas coreografias de Pina Bausch expressam qualidades próprias que deixam incertos os limites entre a dança e o teatro. O processo criativo de Pina Bausch, evidente na obra 1980, baseia-se na experiência de rememorar sentimentos e manifestá-los em gestos. Esse procedimento revela também uma indagação mais arraigada à personalidade e ao inconsciente do bailarino, um trabalho de interioridade do performer com o objetivo de expressar algo que foi cultivado, construído e que de alguma maneira constitui uma personalidade. Trata-se de um processo poético das sensações, isso quer dizer, que o performer, formado por experiências que Ihe geraram qualida- des e sentidos, foi provocado a transformar essas qualidades e sentidos em gestos, ou seja, movimentos plásticos. Nesse momento, o processo criativo do performer expressa uma relação da interioridade à exterioridade, construindo uma ação que estabelece uma relação intersubjetiva com a percepção do espectador e sua experiência de pensamento. É evidente nas encenações que o espectador da dançateatro de Pina Bausch não pode se perder no envolvimento dos sentimentos-gestos que os performers expressam.

Na obra 1980, a repetição por vezes exaustiva coloca o próprio gesto em suspensão, definindo uma determinada temporalidade para apreensão crítica do espectador. Essa suspensão parece se aproximar da chamada "ética do signo", conforme argumentada por Jean Galard (2008). Antes que a gesticulação, como elemento da corporeidade dos bailarinos de Pina Bausch, resuma-se a uma mera exteriorização de natureza íntima ou manifestação de um ser interior, a encenadora organiza as cenas tal como "[...] uma forma produtora de sentido, uma configuração significante que é supérfluo referir a uma origem substancial" (Galard, 2008. p.46). Os gestos cotidianos, encenados teatralmente, podem ser identificados pelo espectador, que the atribue sentidos familiares. Contudo, observa-se que durante o espetáculo, quando a repetição de gestos surge como aparente "reprodução" de cenas do cotidiano, um bailarino começa a servir uma bebida (supõe-se que chá ou café) aos espectadores, de maneira a acusar criticamente uma contemplação passiva. Com aproximadamente uma hora de espetáculo, executando repetidamente uma partitura de movimentos gestuais, os bailarinos deslocam a cena do palco para a plateia de maneira que, ao andar 
em fila indiana, realizam compassadamente os gestos em sincronia com a música, integrando sua ação física aos olhares e às interações dos espectadores. Nesse momento, tanto espectadores como atores integram a cena teatral.

Diferente das encenações de Pina Bausch, José Celso Martinez Correa realiza sua encenação de maneira a evidenciar o ato cênico como acontecimento ritual, não obstante 0 encenador inicia e termina seus espetáculos com músicas que remetem a um estado sublime religioso. No Teat®o Oficina Uzina Uzona, o coletivo se torna um sujeito teatral. Nele, integram-se artistas que executam papéis distintos e colaborativos no processo criativo: o encenador, o dramaturgo, os atores e as atrizes, os músicos, o videomaker, o iluminador, o sonoplasta e os demais técnicos da produção, os quais formam um coletivo de artistas teatrais. A encenação do espetáculo Walmor e Cacilda 64 - Robogolpe, apresentado na sede da cia de teatro em maio e junho de 2014, é iniciado como um ritual. A forma narrativa dramática é usada como recurso para o humor, enquanto surgem em cena formas de um teatro contemporâneo que se apropria da projeção audiovisual de cenas e utiliza da iluminação executada em sincronia aos gestos corporais e à musicalização, algo próximo ao que artistas conceituais do Fluxus tratavam como intermedia. O espectador é constantemente interrogado e, em alguns momentos, é trazido ao centro da cena, ainda que à revelia.

No acontecimento cênico realizado pelo Teatßo Oficina Uzina Uzona, o espectador não pode ficar em inércia contemplativa. Ele é convocado para ser um participante da cena e, nesse sentido, o ator trabalha como um xamã, transcendendo a cena para um estado no qual as dicotomias cotidianas estão suspensas, tal como argumenta Gilberto Icle (2010, p.81). Outro aspecto na perspectiva da cena teatral como acontecimento, concerne à aproximação da atuação dos atores a uma certa performance quando do "[...] uso do corpo humano como sujeito e força motriz do ritual" (Glusberg, 2013, p.11). Esse aspecto da relação arte-vida é evidente nas três obras teatrais que abordamos nesse trabalho.

Há algo em comum entre os atores de 1980 de Pina Baush, de Walmor e Cacilda 64 - Robogolpe de José Celso Martinez Correa e a atuação de Angelica Lidell em Yo no soy bonita, apresentada na Mostra Internacional de Teatro São Paulo, em março de 2014. Na encenação de 1980, uma bailarina "dança" a partir da movimentação de um regador elétrico, instalado e ligado sobre o palco. Ou ainda, em outro momento, uma bailarina coloca objetos em combustão entre os dedos do pé de outro bailarino, de maneira que ele consiga apagá -los no momento em que estes começam a queimá-lo. Ainda assim, a ação hiper-realista de Angélica Lidell de se cortar em cena e se alimentar do próprio sangue retoma, de forma mais evidente, essa estreita relação arte-vida. Criada a partir de uma experiência de abuso sexual sofrido por Angélica Lidell, a performance Yo no soy bonita apresenta uma crítica à sociedade patriarcal e aos papéis que são condicionados às mulheres. Nessa performance, a atriz executa breves e intensos atos, alguns que demonstram a mutilação do corpo, reelaborando poeticamente a violência sexual. Sua ação física se manifesta para além de uma ideia de ficção. A criação cênica deixa de 
ser fantasiosa e passa a agir com hiper-realismo, que pode despertar o incômodo do respectador quando da descoberta que o ato violento é real e doloroso; aqui percebemos a experiência da performer na produção de um sentido que pode vir a ser despertado no espectador.

É difícil dar uma definição à performance, visto que isso nega sua própria ideia de linguagem artística. Considerando as observações de Roselee Goldberg (2006), nenhuma outra forma de expressão artística tem um programa tão ilimitado como a performance. Seu caráter "maleável" e "indeterminado", com o objetivo de colocar a arte em contato direto com o público, foi algo significativo no trabalho dos artistas conceituais no âmbito das artes visuais, embora estivesse presente bem antes nos trabalhos dos dadaístas e surrealistas. Deve-se considerar que as ações realizadas durante encenações teatrais, ao menos aquelas que se aproximam ou se contaminam com a linguagem da performance, revelam alguns aspectos que não são percebidos na forma dramática. São ações empreendidas como maneira de dar vida a ideias formais e conceituais nas quais se baseia a criação cênica, mas que encontraram limitações formais no fazer teatral mais ligado à tradição da representação. São, portanto, provocações e desafios postos às artes cênicas. E, nesse sentido, tanto na performance art quanto em determinadas ações realizadas em encenações teatrais, o performer tem uma variedade infinita de como realizar seu programa ao longo do seu processo criativo e da própria execução da ação. E, dessa maneira, os artistas reafirmam que a ideia é mais importante que o produto, e que esta ideia pode ser entendida a partir de uma relação de intersubjetividade e interatividade entre o artista, a encenação e o espectador. Nesse sentido, o teatro, na estética relacional, revela-se como um campo de tensões entre palco e o espectador.

Tal postura pode ser entendida sob a perspectiva da relação entre estética e política, como propõe Jacques Rancière. Assim, esse teatro de formas relacionais, com intervenções dos artistas a partir das contaminações da performance, reagindo e criticando a forma dramática, acende também essas tensões entre o palco e os seus espectadores. "A política aí se representa como relação entre a cena e a sala, significação do corpo do ator, jogos de proximidade ou distância [em relação ao espectador]" (Rancière, 2009, p.24).

No teatro, as relações de interatividade e intersubjetividade artista/encenação/espectador se assumem como princípios que dão forma à arte teatral, reacendendo o ato cênico como acontecimento ritual e, dessa maneira, reconstituindo uma comunidade emancipada, no sentido que Jacques Rancière emprega a expressão:

\footnotetext{
Os artistas, assim como os pesquisadores, constroem a cena onde a manifestação e o efeito de suas competências são expostos incertos nos termos do idioma novo que traduz uma nova aventura intelectual. $O$ efeito do idioma não pode ser antecipado. Ele solicita dos espectadores que jogam o papel de intérpretes ativos que elaborem sua própria tradução, para se apropriar da "história" fazendo sua própria história. Uma comunidade emancipada é uma comunidade de contadores e de tradutores" (Rancière, 2008, p. 28-29).
}

Realizamos uma breve e ainda incompleta reflexão, articulando aspectos da estética relacional de Nicholas Bourriaud a um fenômeno percebido nas artes cênicas. Pretendo 
desenvolver essa reflexão de maneira mais densa, observando outras questões que cercam o mesmo fenômeno e que não foram abordadas, tal como o work in progress na encenação contemporânea. Certamente, se tentasse aprofundar o tema nesse ensaio, precisaria ter uma reflexão mais longa e profunda. Neste caso, preferimos cercar o fenômeno da intersubjetividade e da interatividade de forma introdutória.

\section{Referências}

ARTAUD, Antonin. Oeuvres. Paris: Gallimard, 2010.

BOURRIAUD, Nicholas. Estética relacional. São Paulo: Martins Fontes, 2009.

FERNANDES, Silvia; GUINSBURG, J. (orgs.). O pós-dramático: um conceito operativo?. São Paulo: Perspectiva, 2010.

GALARD, Jean. A beleza do gesto: uma estética das condutas. São Paulo: Edusp, 2008.

GLUSBERG, Jorge. A arte da performance. São Paulo: Perspectiva, 2013.

GOLDBERG, Roselee. A arte da performance: do futurismo ao presente. São Paulo: Martins Fontes, 2006.

HUGO, Victor. Do grotesco e do sublime. São Paulo: Perspectiva, 2012.

ICLE, Gilberto. O ator como um xamã: configurações da consciência no sujeito extracotidiano. São Paulo: Perspectiva, 2010.

LEHMANN, Hans-Thies. Teatro pós-dramáti- co. São Paulo: Cosac Naify, 2007.

"Teatro pós-dramático e teatro político". In. FERNANDES, Silvia; GUINSBURG, J. (orgs.). O pós-dramático: um conceito operativo?. São Paulo: Perspectiva, 2010. pp. 233254.

LYOTARD, Jean-François. A condição pósmoderna. Lisboa: Gradiva, 1989.

MEYERHOLD, Vsévolod. O teatro de Meyerhold. Tradução, apresentação e organização de Aldomar Conrado. Rio de Janeiro: Civilização Brasileira, 1969.

RANCIÈRE, Jacques. Le spectateur émancipé. Paris: La Fabrique Éditions, 2008.

A partilha do sensível. São Paulo: EXO Experimental org.; Editora 34, 2009.

SZONDI, Peter. Teoria do drama moderno (1880-1905). São Paulo: Cosac Naify, 2011.

Teoria do drama burguês [século XVIII]. São Paulo: Cosac Naify, 2004.

Recebido em 30/11/2014 Aprovado em 25/05/2016 